Prace Filologiczne. Literaturoznawstwo 11(14) 2021

ISSN 2084-6045

e-ISSN 2658-2503

Creative Commons: Uznanie autorstwa 3.0 PL (CC BY)

DOI: $10.32798 /$ pflit.254

\title{
O (NIE)PRZYDATNOŚCI CEZURY ROKU 1600 W HISTORII MUZYKI
}

\author{
On the (Un)Usefulness of the Turning Point of 1600 in the History of Music
}

TOMASZ JEŻ

Uniwersytet Warszawski, Polska

E-mail: tomasz.jez@uw.edu.pl

https://orcid.org/0000-0002-7419-3672

\begin{abstract}
The artistic manifesto of Florentine Camerata is widely regarded as a breakthrough moment not only in musical stylistics but also in theoretical reflection on music. In traditional musicography, the year 1600 appears to be a fairly clear border separating the Renaissance from the Baroque. However, the musical designations of both periods are very vague and their application inevitably leads to contradictions. The solution to these contradictions can be a model of interpretation of the history of music that links musical creation with the current of humanistic inspirations that have been present in European culture at least since the mid-sixteenth century and lasting for the next hundred years. This trend has led to a significant re-evaluation of the issue of style in music, which reflects the concept of mannerism quite well.
\end{abstract}

Keywords: Renaissance, humanism, mannerism, Baroque, periodisation, history of music

Streszczenie

Artystyczny manifest florenckiej Cameraty powszechnie uważa się za przełom nie tylko w stylistyce muzycznej, ale także w teoretycznej refleksji nad muzyką. W tradycyjnej muzykografii cezura roku 1600 jawi się jako dość wyraźna granica oddzielająca renesans od baroku. Muzyczne desygnaty obydwu tych epok są jednak bardzo niejasne, a ich stosowanie nieuchronnie prowadzi do sprzeczności. Za ich rozwiązanie posłużyć może taki model interpretacyjny, który wiąże twórczość muzyczną z nurtem inspiracji humanistycznych, obecnych w kulturze europejskiej co najmniej od połowy wieku XVI i trwających przez kolejne stulecie. Nurt ten doprowadził do znaczącego przewartościowania kwestii stylu w muzyce, co dość dobrze oddaje pojęcie manieryzmu.

Słowa kluczowe: renesans, humanizm, manieryzm, barok, periodyzacja, historia muzyki 
Za jedną z najbardziej wyraźnych cezur w historii muzyki uchodzi przełom wieków XVI i XVII, wyznaczający kres doby renesansu i początek epoki baroku. Schyłek tej pierwszej symbolizuje data śmierci Giovanniego Pierluigiego da Palestriny i Orlanda di Lasso (1594) - kompozytorów najczęściej kojarzonych z muzyką, którą współcześnie określa się mianem renesansowej; za początek muzycznego baroku uznaje się zaś zazwyczaj rok 1600, w którym członkowie florenckiej Cameraty, Jacopo Peri i Giulio Caccini, wystawili Euridice do libretta Ottavia Rinunciniego - pierwszy zachowany do dziś dramma per musica ${ }^{1}$. Narodziny tego gatunku uważa się za przełom nie tylko w zakresie stylu muzycznego, ale także w samym rozumieniu muzyki, które w tym właśnie czasie uległo rewolucyjnym transformacjom. Przemiany te były zresztą przedmiotem rozważań ówczesnych teoretyków muzyki, m.in. samego Cacciniego, który we wstępie do wydanego przez siebie zbioru Le nuove musiche ${ }^{2}$ sformułował własną refleksję teoretyczną na jej temat. Wedle tego autora celem sztuki dźwięku winno być przede wszystkim „poruszanie uczuć ducha” (muovere affetto dell'animo $)^{3}$ wywołane przez melodię, która naśladuje mowę ludzką: zarówno pod względem intonacji, jak i formy, wzorowanej na retorycznej konstrukcji mowy oratora.

Ten nowy styl muzyczny był tak bardzo różny od dotąd kultywowanych tradycji, że manifest artystyczny Cacciniego uznano za cezurę rozpoczynającą zupełnie nową epokę, w której pojawiły się nieznane dotąd gatunki. Muzyce tej epoki nadano później nazwę baroku, zapożyczoną z dyskursu sztuk wizualnych; w odniesieniu do sztuki dźwięku nazwa ta miała oznaczać przeładowanie modulacjami i dysonansami, pogmatwaną harmonię, szorstką i nienaturalną melodię ${ }^{4}$. Tak właśnie jawiła się ona pionierom francuskiego Oświecenia, którzy nie rozumieli, że obecność wszystkich tych środków muzycznej ekspresji w pełni uzasadnia humanistyczna idea podporządkowania muzyki słowu i oddania za pomocą dźwięków ukrytych w nim afektów ${ }^{5}$. Muzyki tej nie rozumieli także współcześni jej narodzinom autorzy, oceniający jej syntaksę z perspektywy klasycznych zasad kontrapunktu. Sporu między teoretykami broniącymi konwencji dotychczasowego stylu (Giovanni Maria Artusi) a praktykami promującymi nowy

${ }^{1}$ R. Haas, Die Musik des Barocks, Wildpark-Potsdam 1928, s. 3.

${ }^{2}$ Le Nuove Musiche di Giulio Caccini detto Romano, Firenze 1601 [1602]. Przekład polski wstępu do tego zbioru w tłumaczeniu Anny Szweykowskiej znajduje się w pracy: Z. M. Szweykowski, Między kunsztem a ekspresją, cz. 1: Florencja, Kraków 1992, s. 224-242; tutaj s. 227.

${ }^{3}$ N. Anderson, Baroque music: from Monteverdi to Handel, London 1994, s. 13-14.

${ }^{4}$ J.-J. Rousseau, Dictionaire de musique, Paris 1768, s. 40: „Muzyka barokowa to taka, której harmonia jest pogmatwana, obarczona modulacjami i dysonansami, melodią ciężką i niezbyt naturalną, trudną intonacją, ograniczonym ruchem. Wydaje się, że termin pochodzi od określenia sylogizmu Baroco, stosowanego przez Logików" (tłumacz. red.).

${ }^{5}$ C. V. Palisca, Baroque music, Englewood Cliffs 1968, s. 3. 
styl muzyki (seconda pratica) i dopuszczającymi możliwość współwystępowania różnych stylów muzycznych (Claudio Monteverdi) nie da się jednak w żaden sposób rozwiązać. Sama więc tożsamość muzycznego baroku, widzianego z perspektywy zarówno epok sąsiadujących, jak i współczesnej - wymaga pogłębionej refleksji badawczej.

Problematyczne są przede wszystkim nazwy obydwu epok (renesans, barok), odnoszone do kultywowanych w nich tradycji muzycznych. Wynika to m.in. stąd, że ich desygnaty określane są za pomocą cech odróżniających muzykę, która powstała przed cezurą roku 1600, od tej, którą napisano bezpośrednio po niej. Zakłada się bowiem, że cezura ze swej definicji oddziela zjawiska historycznie odmienne, wyznaczając moment kresu jednej, a zarazem początek innej grupy zjawisk i właśnie na tym polega jej badawcza przydatność. Jednak to, co definiuje się jako muzyczny renesans oraz barok, oddziela cezura, która - pomimo swej bardzo atrakcyjnej retorycznie wyrazistości - nie stanowi kategorii ani ściśle delimitacyjnej, ani sensu stricto różnicujaccej. Co więcej, stosowane we współczesnym dyskursie naukowym modele periodyzacji historii muzyki w wielu przypadkach z cezurą tą zbytnio się nie wiążą: niektóre z nich zdają się wręcz jej unikać, inne zaś zastępują ją uchodzącymi za bardziej obiektywne nazwami stuleci. Warto jednak zauważyć, że w przypadku Cinquecenta i Seicenta działanie takie paradoksalnie przywraca obecność naszej cezury, choć jej metodologiczny sens jest już diametralnie inny.

Oczywiście, można przyjąć, że cezura wiążąca się z rokiem 1600 jest nie tyle ostrą granica między muzycznym renesansem i barokiem, ile raczej datą symbolizującą okres przejściowy pomiędzy tymi epokami. Rozwiązanie takie zdają się uzasadniać także i inne cezury o podobnej randze, przyjmowane równie często za początek muzycznego baroku: rok 1598 jako data wystawienia Dafne - pierwszego dramma per musica Periego, 1596 - czas ukazania się Szóstej księgi madrygatów Luzzascha Luzzaschiego poprzedzonej wstępem kluczowym dla poruszanych tu problemów ${ }^{6}$; a w naszym polskim kontekście rok 1595 - w którym Zygmunt III Waza dokonał gruntownej reorganizacji kapeli królewskiej, werbując do niej sporą grupę muzyków włoskich ${ }^{7}$. Za porównywalne pod względem historycznego znaczenia cezury uznać też można daty wydania pierwszego zbioru koncertów instrumentalnych Lodovica Viadany (1602) ${ }^{8}$,

${ }^{6}$ L. Luzzaschi, Sesto libro de' madrigali a cinque voci [Ferrara 1596]. Cf. A. Newcomb, The Madrigal at Ferrara 1579-1597, Princeton 1980, s. 118. Cf. przypis 52.

${ }^{7}$ B. Przybyszewska-Jarmińska, Historia muzyki polskiej, t. 3: Barok-część pierwsza. 1595-1696, Warszawa 2006, s. 14.

${ }^{8}$ L. Viadana, Cento concerti ecclesiastici, a una, a due, a tre, \& a quattro voci, con il basso continuo per sonar nell'organo, nova inventione commoda per ogni sorte de cantori, \& per gli organisti [...] opera duodecima [...], [Venezia] 1602. 
Piątej księgi madrygałów Monteverdiego (1605) poprzedzonej słynnym wykładem na temat seconda pratica ${ }^{9}$ czy pierwszej edycji jego Orfeusza $(1607)^{10}$.

Wydarzeń o podobnie ważkiej randze dla badanego tu zjawiska wyliczyć można jednak więcej; zajmą one zresztą znacznie szerszy zakres czasu, którego żadną miarą nie będzie można uznać za przejściowy. Postulat definiujący ten nowy styl muzyki - „aby mowa była panią muzyki, a nie jej sługą” (l'oratione sia padrona del armonia e non serva $)^{11}$ - odnajdujemy w przedmowach do druków muzycznych i w traktatach teorii muzyki z całego XVI w., a nawet wcześniej ${ }^{12}$. Nawet jeśli pod presją wyznaczonej już (w pewien sposób a priori) cezury roku 1600 zawęzimy ten czas do ostatnich dekad XVI w. i jedynie te lata uznamy za wstępną fazę muzycznego baroku ${ }^{13}$, to przecież zmuszeni będziemy do konstatacji, że aktywność florenckiej Cameraty, usiłującej wskrzesić zapomnianą muzykę greckiego antyku, wypływała $\mathrm{z}$ inspiracji na wskroś renesansowych. $\mathrm{Z}$ uwagi jednak na fakt, że cezurę roku 1600 powszechnie uznaje się za początek muzyki barokowej, to najważniejszy historycznie efekt działania Cameraty - narodziny opery - zazwyczaj określa się paradoksalnie mianem fenomenu symptomatycznego nie dla muzycznego renesansu, ale właśnie baroku...

Może zatem należałoby zrezygnować z tej ostatniej etykiety periodyzacyjnej, skoro jej stosowanie tak nieuchronnie prowadzi do sprzeczności? Niemałą odwagą w tej dziedzinie wykazali się pół wieku temu wydawcy The New Oxford History of Music, którzy poświęcone epoce baroku tomy swojej serii zatytułowali, posługując się wyłącznie kryteriami gatunkowymi ${ }^{14}$, a historię powstania seconda pratica opisali w tomie poświęconym muzycznemu humanizmowi ${ }^{15}$. Zaproponowana przez Geralda Abrahama periodyzacja tak rozumianej epoki obejmuje bardzo różnorodne zjawiska kultury muzycznej, wiązane wspólnym mianownikiem humanistycznej orientacji, która skłaniała kompozytorów do ścisłego podporządkowania muzyki słowu: chodzi tu nie tylko o eksperymenty florenckiej Cameraty,

${ }^{9} \mathrm{C}$. Monteverdi, Il quinto libro de madrigali a cinque voci [...] col basso continuo per il clavicembalo, chittarone od altro simile istromento, fatto particolarmente per li sei ultimi, et per li altri a beneplacito, [Venezia] 1605.

${ }^{10}$ L'Orfeo favola in musica da Claudio Monteverdi maestro di capella della Sereniss. Republica rappresentata in Mantova l'anno 1607, Venezia [1607].

${ }^{11}$ Przedmowa do Scherzi musicali di Claudio Monteverde, raccolti da Giulio Cesare Monteverde suo fratello et novamente posti in luce. Con la dichiaratione di una lettera, che si ritrova stampata nel Quinto libro de suoi Madregali [...], Venezia 1607.

${ }^{12}$ C. V. Palisca, Humanism in Italian Renaissance musical thought, New Haven-London 1985 , s. $67-87$.

${ }^{13}$ Historia muzyki w XVII wieku, red. Z. M. Szweykowski, Muzyka we Włoszech, t. 1: Pierwsze zmiany, Kraków 2000, s. 38.

${ }^{14}$ Opera and Church Music. 1630-1750, red. A. Lewis, N. Fortune, London 1975; Concert Music. 1630-1750, red. G. Abraham, London 1986.

${ }^{15}$ The Age of Humanism. 1540-1630, red. G. Abraham, London 1968. 
ale także francuską musique mesurée, angielskie ayres i szkolne opracowania ód metrycznych, protestancką pieśń kancjonałową i okołotrydenckie poszukiwania idealnej muzyki liturgicznej. Interpretacyjne walory tej syntezy osłabia wprawdzie dość radykalny sekularyzm w samym definiowaniu humanizmu; dziś jednak pojęcie to rozumiemy w sposób znacznie bardziej otwarty.

Naturalnie, możemy też pozostać przy pojęciu baroku w odniesieniu do muzyki i traktować je wyłącznie jako poręczną - choć niewiele znaczącą - etykietę; samą zaś sztukę muzyczną epoki definiować za pomocą kryteriów stricte estetycznych. Postępowanie tego typu zaproponował Claude V. Palisca, dla którego wspólnym mianownikiem muzyki barokowej był cel, któremu - zdaniem współczesnych - miała ona służyćc ${ }^{16}$. Zgodnie z sugestią cytowanego wyżej Cacciniego, podporządkowanie melodii słowu wywoływać bowiem miało w odbiorcach odpowiedni afekt, a muzyka winna przede wszystkim poruszać słuchacza, spełniając w ten sposób najważniejszy - w tej perspektywie - postulat triady Kwintyliana (movere). Właśnie to kryterium estetyczne łączy w zaskakująco spójną (choć wewnętrznie zróżnicowaną) całość muzykę komponowaną od czasów Cipriana di Rore aż po Jana Sebastiana Bacha. Za patrona tej epoki Palisca uznał zaś Kartezjusza, który kodyfikuje dotychczasową refleksję na temat teorii afektów i jej związków z filozofią, fizyką i fizjologią ${ }^{17}$.

Koncepcja francuskiego myśliciela wywodzi się m.in. z ówczesnej dydaktyki jezuickiej, która inspirowana różnymi nurtami humanizmu usiłowała odnaleźć właściwą rolę dla człowieka i tworzonej przezeń sztuki ${ }^{18}$. Z tego również źródła wypływała synteza Athanasiusa Kirchera, w której odnajdziemy nie tylko jedna z redakcji katalogu figur retoryki muzycznej, ale także ciekawy wykład na temat roli muzyki w życiu społeczeństw (musica politica) ${ }^{19}$. Obydwie koncepcje uznać można za przejawy spekulatywnej refleksji nad muzyką, wyraźnie odróżniające ją od ujęć typowo renesansowych. O ile te ostatnie charakteryzuje postrzeganie sztuki dźwięku przede wszystkim w perspektywie sztuk retorycznych (trivium), to mechanistyczne ujęcia Kartezjusza i Kirchera (a także innych kodyfikatorów barokowej retoryki muzycznej: od Joachima Burmeistra ${ }^{20}$ po Johannesa Matthesona ${ }^{21}$ )

${ }^{16}$ C. V. Palisca, Baroque music, s. 4-5.

${ }^{17}$ Les passions de l'âme par Réne des Cartes [...], Paris 1649.

${ }^{18}$ N. Anderson, op. cit., s. 8-11.

${ }^{19}$ A. Kircher, Musurgia universalis, sive ars magna consoni et dissoni [...], t. 1, Roma 1650, s. $432-440$.

${ }^{20}$ Musica poetica: definitionibus et divisionibus breviter delineata, quibus in singulis capitibus

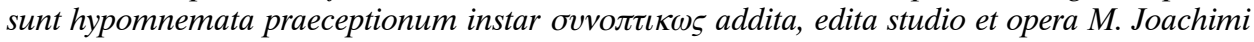
Burmeisteri [...], Rostock 1606.

${ }^{21}$ Der vollkommene Capellmeister, das ist Gründliche Anzeige aller derjenigen Sachen, die einer wissen, können, und vollkommen inne haben mu $\beta$, der einer Capelle mit Ehren und Nutzen vorstehen will: Zum Versuch entworffen von [J.] Mattheson, Hamburg 1739. 
nawiązują ponownie do nieco mniej wyraźnych w XVI w. związków muzyki z dyscyplinami grupy quadrivium. Siedemnastowieczny renesans myśli Boecjusza przywraca bowiem sztuce dźwięku z jednej strony status nauki ścisłej, z drugiej zaś - dyscypliny posługującej się refleksją o charakterze transcendentalnym. Za nowe cechy w tym kontekście uznać zaś możemy zarówno skłonność do systematyzowania języka muzycznej syntaksy, jak i obserwacje na temat mechanizmów „politycznego” funkcjonowania muzyki.

Wątki te wracają we współczesnej refleksji nad muzyką baroku, podejmowanej z perspektywy socjologii historycznej bądź antropologii kulturowej, badaną przede wszystkim jako przejaw przemian społeczno-politycznych XVII w.22, uwikłanego w symbiotyczny układ władzy, religii i służącej im retoryki ${ }^{23}$. Trudno zaprzeczyć tezie o propagandowej funkcji muzyki towarzyszącej wystawianym wtedy spektaklom teatralnym czy nacechowanych podobną pragmatyką dedykacji dołączanych do druków muzycznych ${ }^{24}$. Genezy takiego postrzegania sztuki dźwięku upatrywać można jednak już w ówczesnej refleksji jej teoretyków; przede wszystkim Marca Scacchiego, który muzykę swoich czasów dzielił wedle kryteriów określających jej funkcję, zależną od miejsca jej wykonania: ecclesiastica, cubicularis i theatralis ${ }^{25}$. Autor ten opowiedział się zresztą także po stronie Monteverdiego w jego sporze z Artusim, dopuszczając możliwość istnienia dwóch stylów, diametralnie odmiennych pod względem rządzących nimi prawideł: prima i seconda pratica.

Zasady funkcjonowania tego drugiego stylu wynikały oczywiście ze ścisłego podporządkowania melodii słowu; wedle opinii Angela Berardiego właśnie to kryterium odróżnia sztukę dawnych mistrzów (działających w XVI w.) od kompozytorów jemu współczesnych ${ }^{26}$. Tych ostatnich nie zadowalało bowiem ilustrowanie przez muzykę jedynie wybranych słów tekstu; dążyli oni do odzwierciedlenia za pomocą melodii ukrytego w słowach afektu. Podobnie nowość swojej muzyki opisywał Caccini, który w typowej dla florenckich dilettanti retoryce wyznał, że więcej nauczył się na spotkaniach Cameraty niż w ciągu 30 lat studiowania kontrapunktu ${ }^{27}$. Zawarte $\mathrm{w}$ zbiorze Le nuove musiche utwory rzeczywiście

${ }^{22}$ L. Bianconi, Il Seicento, Torino 1982.

${ }^{23}$ J. W. Hill, Baroque Music: music in Western Europe, 1580-1750, New York-London 2005, s. $1-12$.

${ }^{24}$ T. Carter, Renaissance, Mannerism, Baroque, w: Seventeenth-Century Music, red. T. Carter, J. Butt, Cambridge 2005, s. 15.

${ }^{25}$ A. Patalas, $W$ kościele, $w$ komnacie $i w$ teatrze. Marco Scacchi: życie, muzyka, teoria, Kraków 2010, s. 384.

${ }^{26}$ Miscellanea musicale di D. Angelo Berardi da S. Agata, canonico nell'insigne collegiata di $S$. Angelo di Viterbo, divisa in tre parti dove con dottrine si discorre delle materie più curiose della musica: con regole, et essempii si tratta di tutto il contrapunto con l'intreccio di bellissimi secreti per li professori armonici [...], Bologna 1689.

${ }^{27}$ Z. M. Szweykowski, op. cit., s. 226. 
stanowią novum pod względem stylu; w ich omówieniu Caccini ignoruje jednak (w pragmatycznie świadomy sposób) fakt, że obydwa sposoby ilustrowania słowa muzyką były znane zarówno w dotychczasowej praktyce, jak i w teorii muzycznej. Nie brakowało bowiem w muzyce XVI w. praktycznych realizacji humanistycznych ideałów; rozróżnienie między kategoriami imitazione della parola i imitazione della natura delle parole stanowiło jedno z loci communes renesansowej teorii muzyki ${ }^{28}$.

Wydaje się więc, że u źródeł popularności cezury roku 1600 stoi arbitralnie nieobiektywna opinia Cacciniego-teoretyka, który, chwaląc nowość stylu muzycznego utworów Cacciniego-kompozytora, pomija te elementy refleksji teoretycznej, które świadczą o ciąłości nurtu muzyki podporządkowanej słowu. Oczywiście, łatwiej nam dziś zrozumieć postawę Cacciniego niż Berardiego; jako usprawiedliwienie tego drugiego autora może jednak posłużyć późniejsza interpretacja tamtych zjawisk stylistycznych, nawet jeśli bywa ona formułowana w sposób zwykle metaforyczny ${ }^{29}$. W podobne uproszczenia obfituja zresztą także historyczne deklaracje takich członków Cameraty, jak Vincenzo Galilei $^{30}$ czy Giovanni de’ Bardi ${ }^{31}$. Ich narrację łączy jednak świadomość zupełnie nowej koncepcji sztuki muzycznej, wyraźnie odmiennej od ujęć teoretyków wcześniejszych. O ile bowiem dla tych ostatnich muzyka stanowić miała sztukę samodzielną, opartą na autonomicznych dla niej zasadach, teoretycy Cameraty uznawali ją za sztukę heteronomiczną i służącą jasno określonym celom $^{32}$. Obu tych modeli nie da się w żaden sposób pogodzić, co dodatkowo polaryzuje estetyczne oceny materii muzycznej pochodzacej z obydwu stron dyskutowanej cezury.

Koncept związany z rokiem 1600 wpływa także na nasze postrzeganie epoki wcześniejszej, zwykle zwanej renesansem. O ile w historii europejskiej kultury jawi się ona w sposób bezdyskusyjnie wyraźny, to w odniesieniu do samej muzyki jej desygnat wygląda na tyle niejasno, że autorzy częściej wolą pisać o muzyce

${ }^{28}$ R. J. Wieczorek, Ut cantus consonet verbis: zwiazki muzyki ze stowem we włoskiej refleksji muzycznej XVI wieku, Poznań 1995, s. 65-67.

${ }^{29}$ M. Bukofzer, Muzyka w epoce baroku. Od Monteverdiego do Bacha, thum. E. Dziębowska, Warszawa 1970, s. 20: „Renesans sprzyjał uczuciom powściągliwym, nacechowanym szlachetną prostotą, barok - namiętnym emocjom od bezmiernego cierpienia do niepohamowanej radości. Oczywiście, przedstawianie tak dużej skali stanów uczuciowych wymagało bogatszego języka muzycznego niż w okresie renesansu".

${ }^{30}$ V. Galilei, Dialogo della musica antica et della moderna [...], Firenze 1581. Cf. Z. M. Szweykowski, op. cit., s. 190-221.

${ }^{31}$ Discorso mandato da Giovanni de' Bardi a Giulio Caccini detto Romano sopra la musica antica, e'l cantar bene... (1578). Przekład polski cf. Z. M. Szweykowski, op. cit., s. 169-187; tutaj s. 175: „Powiadam zatem, że muzyka uprawiana w dzisiejszych czasach dzieli się na dwie części: jedna to ta, która się zowie kontrapunktem, drugą będziemy nazywać sztuką dobrego śpiewu".

${ }^{32}$ M. Bukofzer, op. cit., s. 23. 
w czasach renesansu ${ }^{33}$, niż definiować to, czym miałaby być muzyka renesansowa. Nawet jeśli zgodzimy się co do tego, że kompozycje powstałe przed rokiem 1600 charakteryzuje daleko posunięta jedność stylistyczna, osiagana za pomocą rytmiki menzuralnej, polifonii opartej na interwale tercji i homogenicznej fakturze polifonii imitacyjnej ${ }^{34}$, to nie wiadomo, na czym miałaby polegać renesansowość którejkolwiek z tych cech. Zdecydowanie łatwiej desygnat ten odnajdziemy w siedemnastowiecznym dramma per musica, będącym faktycznym ucieleśnieniem starań Cameraty o odrodzenie muzyki antyku ${ }^{35}$. Jeśli jednak aktywność tego środowiska uznamy za przejaw muzycznego renesansu, to chyba powinniśmy do niego zaliczyć również i inne zjawiska, zrodzone z tej samej, humanistycznej inspiracji? Rok 1600 byłby tu zatem nie cezurą, ale jedną z kulminacji (może nawet najwyraźniejszą) tak rozumianej „epoki humanizmu”, obejmującej zjawiska omawiane m.in. w pracy pod redakcją Geralda Abrahama ${ }^{36}$. Problem polega jednak na tym, że ustanowiona przezeń data rozpoczynająca tak definiowaną epokę (1540) nie uwzględnia wielu wcześniejszych zjawisk podobnej natury. Ich obecność w muzyce europejskiej (przede wszystkim włoskiej) obserwujemy zaś już od początku wieku XIV, który w większości modeli periodyzacji historii muzyki zaliczany jest z kolei do epoki średniowiecza.

W jaki sposób jednak uzasadnić średniowieczny charakter muzyki włoskiego trecenta, pisanej do tekstów Petrarki lub Boccaccia i wykonywanej w palazzi renesansowych dworów Italii? Jak przekonać studentów muzykologii do tego, że ballata okresu trecenta nie ma nic wspólnego z giustinianą epoki quattrocenta, a szesnastowieczny madrygał jest ontycznie różny od madrygału czternastowiecznego? Jeżeli w najstarszej definicji tego gatunku odnajdujemy te same słowa, które trzy wieki później powtórzą Caccini i Monteverdi ${ }^{37}$, jak poważnie traktować cezury lat 1450 i 1600 wyznaczające ponoć początek i koniec muzycznego renesansu? Jak wreszcie - mając przed oczami ewidentnie włoska genezę tego zjawiska - zgodzić się z powszechnie obowiązującą definicją tej epoki jako czasu dominacji tzw. polifonii franko-flamandzkiej $?^{38}$ Przecież fakt, że niektórzy z reprezentantów tej szkoły działali jakiś czas na terenie Italii, nie czyni automatycznie ich twórczości ani włoską, ani renesansową. Może zatem, dla lepszego

${ }^{33}$ H. M. Brown, Music in the Renaissance, Englewood Cliffs 1976.

${ }^{34}$ G. Reese, Music in the Renaissance, New York 1954, s. 3.

${ }^{35}$ A. Della Corte, G. Pannain, Storia della musica, t. 1: Dal medioevo al. Seicento, Torino 1944, s. 363-377.

${ }^{36}$ The Age of Humanism.

${ }^{37}$ Delle rime volgari. Trattato di Antonio da Tempo giudice padovano composto nel 1332, red. G. Grion, Bologna 1869, s. 139: „Brzmienie zaś madrygału, zgodnie ze współczesną praktyką muzyczną, musi być piękne, a melodia winna posiadać pewne cechy sielanki albo madrygału, aby współgrała ze słowami” (tłum. B. Czarski).

${ }^{38}$ T. Carter, op. cit., s. 5-7. 
rozumienia naszej przeszłości, winniśmy nieco zrelatywizować znaczenie cezur i posługiwać się pojęciami nie epok, ale nurtów? Postępowanie takie często prowadzi do nowych interpretacji, które wpuszczają sporo świeżego powietrza do dawno niewietrzonych pomieszczeń historycznego dyskursu ${ }^{39}$.

O tym, jak szeroko należałoby otworzyć okna muzykologicznej refleksji na problem muzyki przełomu XVI i XVII w., pośrednio świadczą trudności z wprowadzeniem do niej na stałe pojęcia manieryzmu. I nie chodzi tu wcale o forsowanie koncepcji istnienia samodzielnej epoki oznaczanej tą właśnie nazwą ${ }^{40}$, lecz o próbę odpowiedzi na pytanie, czy stosowane przez szesnastowiecznych autorów pojęcie miało jakieś odniesienia do powstającej w tym czasie twórczości muzycznej. Aby odpowiedzieć na to pytanie możliwie obiektywnie, powinniśmy odnaleźć historyczny desygnat dyskutowanego pojęcia, odrzucić zaś jego późniejsze interpretacje uznające manieryzm za styl zmanierowany bądź dekadencki ${ }^{41}$. Dobrze też będzie, jeśli zdystansujemy się od poszukiwań analogii między sztukami plastycznymi a muzyką (zbyt często prowadzą one bowiem na manowce) i desygnatu tego pojęcia poszukamy w źródłach z epoki. Nie będziemy tu też komentować dość już bogatej literatury przedmiotu ${ }^{42}$, skupiając się tylko na wątkach związanych bezpośrednio z poruszaną tutaj problematyką.

Etymologia pojęcia manieryzm wywodzi się z włoskiego słowa maniera, określającego elegancki sposób dworskiego zachowania. Dzięki publikacji Il libro del Cortegiano Baldassare'a Castiglionego $(1528)^{43}$ pojęcie to trafiło do pism teoretyków sztuk przedstawiajacych, m.in. Giorgia Vasariego, dla którego maniera oznaczała świadomie stosowaną stylizację artystyczną ${ }^{44}$. W połowie XVI w. pojęcie to

\footnotetext{
${ }^{39}$ N. Pirrotta, Novelty in Italy 1300-1600, w: Music and Culture in Italy from the Middle Ages to the Baroque: A Collection of Essays, Cambridge 1984, s. 159-174.

${ }^{40}$ Z. M. Szweykowski, Czy istnieje manieryzm jako okres $w$ historii muzyki, „Muzyka” 1973, nr 18/1, s. 32-39; V. Ravizza, Manierismus - ein musikgeschichtlicher Epochenbegriff?, „Die Musikforschung” 1981, nr 34/3, s. 273-284.

${ }^{41} \mathrm{~J}$. Haar, Classicism and Mannerism in the 16th-Century Music, „The International Review of Music Aesthetics and Sociology” 1970, nr 1, s. 55-68; L. Finscher, Gesualdos „Atonalität” und das Problem des musikalischen Manierismus, „Archiv für Musikwissenschaft” 1972, nr 29/1, s. 1-16.

${ }^{42} \mathrm{Z}$ najważniejszych prac na ten temat wymienimy tu jedynie następujące: L. Schrade, Von der „Maniera” der Komposition in der Musik des 16. Jahrhunderts, „Zeitschrift für Musikwissenschaft” 1934, nr 16, s. 3-20, 98-117, 152-170; L. H. Lockwood, On 'Mannerism' and 'Renaissance' as Terms and Concepts in Music History, „Studi musicali” 1973, nr 3, s. 85-100; C. V. Palisca, Towards an Intrinsically Musical Definition of Mannerism in the Sixteenth Century, „Studi musicali” 1974, nr 3, s. 313-331.

${ }^{43}$ H. Miedema, Mannerism and maniera, „Simiolus: Netherlands Quarterly for the History of Art” 1978-1979, nr 10/1, s. 40.

${ }^{44}$ G. Vasari, Le vite de' più eccellenti pittori, scultori e architettori, Firenze 1550, Proemio della terza parte: „Leonardo da Vinci, zapoczątkowując ową trzecią manierę, którą my chcemy nazywać nowoczesną, oprócz wigoru i zręczności rysunku i oprócz subtelnego naśladowania wszystkich szczegółów natury [...] naprawdę poruszał i ożywiał swoje wizerunki”.
} 
zadomowiło się również w traktatach teorii muzyki ${ }^{45}$, gdzie określało styl kompozytora powszechnie uznanego za doskonałego i z tej racji godnego naśladowania (imitazione authorum). Za przykład takiej perfekcji stylistycznej Gioseffe Zarlino uznał muzykę Adriana Willaerta ${ }^{46}$. Podobnie manierę rozumiał Nicola Vicentino, który odróżniał ten termin od określenia modo do comporre, oznaczającego zwykły (tj. pozbawiony wartościującej przydawki) sposób komponowania ${ }^{47}$. Maniera wskazuje tu na najwyższy poziom doskonałości artystycznej, określany mianem somma altezza ${ }^{48}$ albo po prostu jako perfecta ars cui ut nihil addi potest ${ }^{49}$.

Być może to właśnie ta ostatnia definicja, użyta przez Heinricha Glareana dla opisania twórczości muzycznej Josquina dés Prés (1450-1521), wiąże się z faktycznym historycznie desygnatem manieryzmu w historii muzyki. Byłby nim zatem dominujący w II połowie XVI w. nurt świadomej stylizacji idealnego muzycznie stylu: dla twórców tej epoki za wzór doskonałości uchodziła twórczość Josquina, którego datę śmierci coraz częściej uznaje się za kluczową cezurę w periodyzacji historii muzyki ${ }^{50}$. Kto wie, czy nie była to cezura nawet ważniejsza od tej wyznaczającej kres życia Lassa i Palestriny. Obydwaj ci twórcy byli - jak wiadomo podobnie podziwiani przez współczesnych, a po roku 1594 ich styl stanowił powszechnie obowiązujący i często naśladowany wzorzec doskonałości. Kompozycje utrzymane w stylu Lassa lub Palestriny obejmowały zresztą znaczącą większość twórczości muzycznej XVII w., określanej przez północnowłoskich awangardzistów mianem prima pratica. Warto tu przypomnieć, że styl seconda pratica kultywowany był zaledwie w kilkunastu muzycznych ośrodkach Europy i jego nazwą określić można niewielką w sumie część komponowanego wówczas repertuaru. Niemal wszyscy zaś twórcy, eksperymentujący ze stylem opisywanym przez Cacciniego, pisali równocześnie utwory utrzymane w pierwszej praktyce.

Wróćmy jednak do manieryzmu i próby znalezienia jego muzycznego desygnatu. To, co w twórczości Josquina budziło zachwyt współczesnych, określało się wtedy mianem musica poetica: muzyki stanowiącej organiczną jedność z tekstem

${ }^{45}$ M. R. Maniates, Mannerism in Italian Music and Culture 1530-1630, Chapel Hill 1978, s. $232-259$.

${ }^{46}$ G. Zarlino, Le istitutioni harmoniche, Venezia 1558, t. 1: Proemio, k. If: „Adrian Willaert, doprawdy jeden z najwybitniejszych umysłów, wprawiony również w praktyce muzycznej, precyzyjnie określając, niczym nowy Pitagoras, co w niej może się pojawić i znajdując niezliczone błędy, zaczą je usuwać; i aby doprowadzić ją [praktykę muzyczną] do tej czci i rangi, które wcześniej miała i które słusznie mieć powinna, ukazał właściwą kolejność układania każdej muzycznej pieśni w sposób elegancki, a swoimi kompozycjami dał tego najjaśniejszy przykład".

${ }^{47} \mathrm{~N}$. Vicentino, L'antica musica ridotta alla moderna prattica, con la dichiaratione, et con essempi dei tre generi, con le loro spetie [...], Roma 1555, lib. IV, cap. 33, k. 90v.

${ }^{48} \mathrm{G}$. Zarlino, Le istitutioni harmoniche [...], loc. cit.

${ }^{49}$ Glareani $\triangle O \triangle E K A X O P \triangle O N$ [Basel 1547], lib. III, cap. 3, s. 241.

${ }^{50}$ Cf. European Music 1520-1640, red. J. Haar, Woodbridge 2006, s. vii. 
słownym $^{51}$. Termin ten - wywodzący się ewidentnie z inspiracji humanistycznej pojawiał się w traktatach teoretycznych XVI w. nader często ${ }^{52}$. Stosujący go autorzy często wyrażali przekonanie, że muzyka ze swojej natury bliższa jest sztukom domeny trivium niż dyscyplinom quadrivium. W podobny sposób wypowiadali się także sami kompozytorzy, którzy potwierdzali, że istotą nowego stylu (maniery) jest właśnie bliźniacza natura poezji i muzyki oraz wynikająca stąd zależność sztuki dźwięku od sztuki słowa ${ }^{53}$. Co ciekawe, pojęcie musica poetica pojawia się równie często w pracach teoretycznych XVII w., szczególnie tych autorów, którzy zarazem kodyfikują zasady posługiwania się retoryką muzyczną ${ }^{54}$. Jeśli nie jest to przypadek, obydwa zjawiska należałoby uznać za przejawy tego samego nurtu: wywodzącego się z ideału renesansowego, koncypowanego za pomocą estetyki manierystycznej i prowadzącego do wykształcenia się stylu zwanego barokowym. Tożsamość ideową tego nurtu, znaczącego swą obecność

${ }^{51}$ N. Pirrotta, op. cit., s. 173.

${ }^{52}$ H. Faber, Musica poetica (1548); G. Dressler, Praecepta musicae poeticae (1563).

${ }^{53}$ Dedykacja do Sesto Libro de' Madrigali a cinque voci di Luzzasco Luzzaschi..., Ferrara 1596. Cyt. za: A. Newcomb, op. cit., s. 277-278: „Najjaśniejsza Pani, muzyka i poezja są tak bardzo do siebie podobne i ze swojej natury pokrewne, że słusznie można powiedzieć (nie bez tajemnicy o nich bajając), że obydwie narodziły się z jednego porodu. I czy lepiej nie zrozumie tego Wasza Wysokość, która widziała tak wiele ich portretów [uczynionych] z natury i która poznała tak dobrze istotę jednej i drugiej. Te dwie bliźniaczki podobne są nie tylko pod względem zachowania się i wyglądu, lecz bardziej cieszą się podobieństwem zwyczajów i szat. Jeśli jedna zmieni swój kszałt, zmienia go również i druga. Dlatego też celem muzyki jest nie tylko użyteczność i przyjemność - najbardziej naturalne cechy jej siostry - ale łagodność, słodycz, powaga, przenikliwość, dowcip i żywotność, co są tymi szatami, w które one tak bardzo wdzięcznie się stroją, jedna i druga noszą je w tak podobny sposób, że często muzyk - poetę, a poeta muzyka przypomina. Ale ponieważ najpierw narodziła się poezja, dlatego ją, jako swą panią, czci muzyka i wielbi: do tego stopnia, że stawszy się niemal jej cieniem, nie śmie poruszyć stopą tam, gdzie starsza już była. Dlatego gdy poeta sięga po styl wysoki, muzyk zwykł podnosić ton. Płacze, jeśli wers płacze, śmieje, jeśli się śmieje, jeśli biegnie, jeśli zatrzymuje się, jeśli błaga, jeśli odmawia, jeśli krzyczy, jeśli milczy, jeśli żyje, jeśli umiera - wszystkie te emocje i czynności tak gorliwie on wyraża, iż ona wydaje się z nim współzawodniczyć. Przeto postrzegamy muzykę naszych czasów nieco inaczej od tej, która była dawniej, ponieważ poezja współczesna różni się od przeszłej. Pomijając wszystkie inne gatunki, które nie zmieniły się, chyba że pod względem treści, jak: kancony, sekstyny, sonety, oktawy i tercyny, powiem o madrygale, który, jak się wydaje, wynaleziony został tylko dla muzyki i, prawdę rzekę, mówiąc, że dopiero w naszych czasach osiągnął najdoskonalszą formę, tak odmienną od dawnej, że gdyby ci pierwsi rymotwórcy ożyli, $\mathrm{z}$ wielkim trudem zdołaliby go [il madrigale] rozpoznać, tak zmieniony się jawi pod względem krótkości, przenikliwości, wdzięku, szlachetności i - wreszcie - słodyczy, którymi przyprawili go poeci, co dziś tworzą. Naśladując ich godny pochwały styl, naszym muzykom udało się wynaleźć nowe sposoby i pomysły, słodsze i wdzięczniejsze od tych dotąd stosowanych, z których uczyniono nową manierę [podkr. - T.J.], która nie tylko z uwagi na swoją nowoczesność, ale także znakomitość sztuki może się podobać i zasłużyć na uznanie świata [...]”.

${ }^{54}$ Poza wspomnianym wyżej traktatem Burmeistra (cf. przypis 20) na uwagę zasługują tu także podobnie tytułowane prace Johannesa Nuciusa (Musices poeticae, sive de compositione cantu, Nysa 1613) i Johanna Andreasa Herbsta (Musica poetica, Nürnberg 1643). 
najwyraźniej w kompozycjach muzycznych powstałych w latach 1550-1650, wiązałaby kategoria mimesis, dookreślana przez teoretyków muzyki jako imitazione authorum, imitazione delle parole oraz imitazione della natura delle parole. Może zatem rok 1600 należałoby uznawać nie za cezurę, ale swego rodzaju przesilenie tak definiowanej formacji stylistycznej?

\section{Bibliografia}

\section{Stare druki}

Der vollkommene Capellmeister, das ist Gründliche Anzeige aller derjenigen Sachen, die einer wissen, können, und vollkommen inne haben muß, der einer Capelle mit Ehren und Nutzen vorstehen will: Zum Versuch entworffen von [Johannes] Mattheson, Hamburg 1739.

Discorso mandato da Giovanni de' Bardi a Giulio Caccini detto Romano sopra la musica antica, e'l cantar bene [...] (1578).

Dressler, Gallus, Praecepta musicae poeticae (1563).

Faber, Heinrich, Musica poetica (1548).

Galilei, Vincenzo, Dialogo della musica antica et della moderna [...], Firenze 1581.

Glareani $\triangle O \triangle E K A X O P \triangle O N$ [Basel 1547].

Herbst, Johann Andreas, Musica poetica, Nürnberg 1643.

Kircher, Athanasius, Musurgia universalis, sive ars magna consoni et dissoni [...], Roma 1650.

Le Nuove Musiche di Giulio Caccini detto Romano, Firenze 1601 [1602].

Les passions de l'âme par Réne des Cartes [...], Paris 1649.

L'Orfeo favola in musica da Claudio Monteverdi maestro di capella della Sereniss. Republica rappresentata in Mantova l'anno 1607, Venezia [1607].

Luzzaschi, Luzzascho, Sesto libro de' madrigali a cinque voci [Ferrara 1596].

Miscellanea musicale di D. Angelo Berardi da S. Agata, canonico nell'insigne collegiata di S. Angelo di Viterbo, divisa in tre parti dove con dottrine si discorre delle materie più curiose della musica: con regole, et essempii si tratta di tutto il contrapunto con l'intreccio di bellissimi secreti per li professori armonici [...], Bologna 1689.

Monteverdi, Claudio, Il quinto libro de madrigali a cinque voci [...] col basso continuo per il clavicembalo, chittarone od altro simile istromento, fatto particolarmente per li sei ultimi, et per li altri a beneplacito, [Venezia] 1605.

Musica poetica: definitionibus et divisionibus breviter delineata, quibus in singulis capitibus

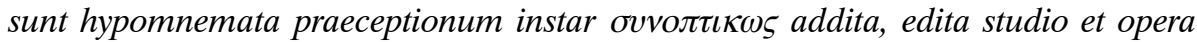
M. Joachimi Burmeisteri [...], Rostock 1606.

Nucius, Johannes, Musices poeticae, sive de compositione cantu, Nysa 1613.

Rousseau, Jean-Jacques, Dictionaire de musique, Paris 1768.

Scherzi musicali di Claudio Monteverde, raccolti da Giulio Cesare Monteverde suo fratello et novamente posti in luce. Con la dichiaratione di una lettera, che si ritrova stampata nel Quinto libro de suoi Madregali [...], Venezia 1607. 
Sesto Libro de’ Madrigali a cinque voci di Luzzasco Luzzaschi [...], Ferrara 1596.

Vasari, Giorgio, Le vite de' più eccellenti pittori, scultori e architettori, Firenze 1550.

Viadana, Lodovico, Cento concerti ecclesiastici, a una, a due, a tre, \& a quattro voci, con il basso continuo per sonar nell'organo, nova inventione commoda per ogni sorte de cantori, \& per gli organisti [...] opera duodecima [...], [Venezia] 1602.

Vicentino, Nicola, L'antica musica ridotta alla moderna prattica, con la dichiaratione, et con essempi dei tre generi, con le loro spetie [...], Roma 1555.

Zarlino, Gioseffo, Le istitutioni harmoniche, Venezia 1558.

\section{Opracowania}

The Age of Humanism. 1540-1630, red. G. Abraham, London 1968.

Anderson, Nicholas, Baroque music: from Monteverdi to Handel, London 1994.

Bianconi, Lorenzo, Il Seicento, Torino 1982.

Brown, Howard M., Music in the Renaissance, Englewood Cliffs 1976.

Bukofzer, Manfred, Muzyka w epoce baroku. Od Monteverdiego do Bacha, tłum. E. Dziębowska, Warszawa 1970.

Carter, Tim, Renaissance, Mannerism, Baroque, w: Seventeenth-Century Music, red. T. Carter, J. Butt, Cambridge 2005.

Concert Music. 1630-1750, red. G. Abraham, London 1986.

Della Corte, Andrea, Pannain, Guido, Storia della musica, t. 1: Dal medioevo al. Seicento, Torino 1944.

Delle rime volgari. Trattato di Antonio da Tempo giudice padovano composto nel 1332, red. G. Grion, Bologna 1869.

European Music 1520-1640, red. J. Haar, Woodbridge 2006.

Finscher, Ludwig, Gesualdos „Atonalität” und das Problem des musikalischen Manierismus, „Archiv für Musikwissenschaft” 1972, nr 29/1.

Haar, James, Classicism and Mannerism in the 16th-Century Music, „The International Review of Music Aesthetics and Sociology" 1970, nr 1.

Haas, Robert, Die Musik des Barocks, Wildpark-Potsdam 1928.

Hill, John Walter, Baroque Music: music in Western Europe, 1580-1750, New York-London 2005.

Historia muzyki w XVII wieku, red. Z. M. Szweykowski, Muzyka we Włoszech, t. 1: Pierwsze zmiany, Kraków 2000.

Lockwood, Lewis H., On 'Mannerism' and 'Renaissance' as Terms and Concepts in Music History, „Studi musicali” 1973, nr 3.

Maniates, Maria R., Mannerism in Italian Music and Culture 1530-1630, Chapel Hill 1978.

Miedema, Hessel, Mannerism and maniera, „Simiolus: Netherlands Quarterly for the History of Art” 1978-1979, nr 10/1.

Newcomb, Anthony, The Madrigal at Ferrara 1579-1597, Princeton 1980.

Opera and Church Music. 1630-1750, red. A. Lewis, N. Fortune, London 1975.

Palisca, Claude V., Baroque music, Englewood Cliffs 1968.

Palisca, Claude V., Humanism in Italian Renaissance musical thought, New Haven-London 1985. 
Palisca, Claude V., Towards an Intrinsically Musical Definition of Mannerism in the Sixteenth Century, „Studi musicali” 1974, nr 3.

Patalas, Aleksandra, $W$ kościele, $w$ komnacie $i w$ teatrze. Marco Scacchi: życie, muzyka, teoria, Kraków 2010.

Pirrotta, Nino, Novelty in Italy 1300-1600, w: Music and Culture in Italy from the Middle Ages to the Baroque: A Collection of Essays, Cambridge 1984.

Przybyszewska-Jarmińska, Barbara, Historia muzyki polskiej, t. 3: Barok-czesść pierwsza. 1595-1696, Warszawa 2006.

Ravizza, Victor, Manierismus - ein musikgeschichtlicher Epochenbegriff?, „Die Musikforschung” 1981, nr 34/3.

Reese, Gustave, Music in the Renaissance, New York 1954.

Schrade, Leo, Von der „Maniera” der Komposition in der Musik des 16. Jahrhunderts, „Zeitschrift für Musikwissenschaft” 1934, nr 16.

Szweykowski, Zygmunt M., Czy istnieje manieryzm jako okres $w$ historii muzyki, „Muzyka” 1973, nr 18/1.

Szweykowski, Zygmunt M., Między kunsztem a ekspresją, cz. 1: Florencja, Kraków 1992.

Wieczorek, Ryszard J., Ut cantus consonet verbis: zwiazki muzyki ze słowem we włoskiej refleksji muzycznej XVI wieku, Poznań 1995.

TOMASz JEŻ studiował muzykologię w Warszawie, Getyndze i Berlinie (jako stypendysta Deutsche Akademische Austauschdienst). Pracuje w Instytucie Muzykologii Uniwersytetu Warszawskiego, od roku 2020 na stanowisku profesora uczelni. Jest autorem 70 artykułów i czterech książek, m.in. monografii Kultura muzyczna jezuitów na Śląsu i ziemi kłodzkiej 1581-1776 (2013), wydanej także w thumaczeniu angielskim (2019) oraz katalogu Danielis Sartorii Musicalia Wratislaviensia (2017). Od 2015 r. jest kierownikiem grantu pt. Repertuar muzyczny Towarzystwa Jezusowego w Rzeczpospolitej Obojga Narodów (1565-1773), finansowanego przez Narodowy Program Rozwoju Humanistyki. W ramach tego projektu koordynuje prace międzynarodowego zespołu muzykologów; efekty tej współpracy publikowane są na stronie założonej przezeń serii wydawniczej Fontes Musicae in Polonia (www.fontesmusicae.pl). Głównym obszarem jego zainteresowań naukowych jest kultura muzyczna Europy Środkowo-Wschodniej w czasach nowożytnych. 